\title{
Correspondence
}

\section{Phosphorylation of $\mathrm{H} 3$ serine 10 by IKK $\alpha$ governs cyclical production of ROS in estrogen-induced transcription and ensures DNA wholeness}

\author{
Cell Death and Differentiation (2014) 21, 1503; doi:10.1038/cdd.2014.91; published online 27 June 2014
}

\section{Dear Editor,}

A growing body of evidence indicates that several modifications on adjacent nucleosomal histone residues (marks) work in a combinatorial fashion to control access to DNA of multiple proteins involved in transcription, replication and repair. ${ }^{1}$ In fact, the 'methyl/ phos switch' hypothesis states that phosphorylation of serine 10 in histone H3 (H3S10) during activation of gene expression controls the methylation level of the preceding lysine (H3K9) by inhibiting recruitment of histone methyltransferase (HMT) factors to that site. ${ }^{2}$ However, it has also been found that addition of the dimethyl group to the same lysine in synthetic $\mathrm{H} 3$ oligopeptides reduces approximately to one-third ability of the following serine to be phosphorylated in vitro. ${ }^{2}$

We have analyzed by chromatin immunoprecipitation (ChIP) the $\mathrm{K} 9 / \mathrm{S} 10$ cross-talk in the estrogen receptor-expressing $\left(\mathrm{ER} \alpha^{+}\right)$ human breast cancer MCF-7 cells depleted or not of the lysinespecific demethylase 1 (LSD1) that removes the methyl group from mono- and dimethylated lysine 9 in histone $\mathrm{H} 3 .{ }^{3}$ Permanence of H3K9me2 near the paradigmatic E2-responsive pS2 promoter in LSD1-interfered cells challenged with $17 \beta$-estradiol (E2) prevented addition of the phosphoryl group to the following site, revealing to represent a pre-requisite for that modification, thus upgrading the current version of the 'methyl/phos' switch theory (Supplementary Figure 1A). Therefore, we have investigated the molecular mission of H3S10 phosphorylation in the transcriptional control by estrogens.

Upon parallel ChIPs in cells where the ER $\alpha$-associated IKK $\alpha$ (that is the kinase responsible for phosphorylation of $\mathrm{H} 3 \mathrm{~S} 10)^{4}$ had been knocked down with siRNAs, we have observed that absence of H3S10ph accelerated of $\sim 30$ min targeting of the HMT Suv39H1 to pS2 promoter. Moreover, in the same cells, H3K9me2 was constantly high, in spite of the concomitant presence of LSD1 (Supplementary Figure 1B). We imagined that this pattern could depend on the opposite action of LSD1 and Suv39H1, both present on chromatin, and consequently, as ER $\alpha$-triggered demethylation of H3K9me2 by LSD1 produces reactive oxygen species (ROS) with oxidation of guanines (8-oxo-Gs) in flanking DNA, ${ }^{5}$ we have assessed the accumulation of oxidized bases around pS2 promoter. Silencing of IKK $\alpha$ in E2-challenged cells resulted into an increased presence of either 8-oxo-Gs as well as of the baseexcision repair enzyme 8-oxo-guanine-DNA glycosylase 1 (OGG1, that cooperates in the removal of modified Gs upon formation of nicks on DNA) ${ }^{6}$ and into a hampered transcription of $p S 2$ gene (Supplementary Figure 1B). On the basis of these observations, we have supposed that persistent and high levels of oxidized bases could damage DNA and that rupture of DNA integrity could trigger programmed cell death.

In fact, evaluation of poly(ADP-ribose) polymerase (PARP) cleavage as marker of apoptosis in cells challenged with E2 for $24 \mathrm{~h}$ in the presence or absence of the specific kinase inhibitor BAY11-7082 (BAY) ${ }^{7}$ added for the first $6 \mathrm{~h}$ (a time sufficient to eventually accumulate ROS during cyclical activation of transcription by estrogens) ${ }^{8}$ revealed that PARP fragmentation was clearly augmented by concomitant addition of BAY and E2 (Supplementary Figure 1C). This effect was mediated by the estrogen receptor, as it was not observed in the $\mathrm{ER} \alpha^{-}$breast cancer MDA-MB-231 cell line, and by produced ROS, as revealed by treatment with their scavenger $\mathrm{N}$-acetyl cysteine that reverted the increase of apoptotic cells treated with BAY and E2, a finding that was confirmed also by FACS analysis (Supplementary Figure 1C). Thus, inhibition of IKK $\alpha$ switched the effect of estrogens on MCF-7 cells from anti- to proapoptotic.

The role of phosphorylation of $\mathrm{H} 3 \mathrm{~S} 10$ in the transcriptional process governed by estrogens pictures a novel use of E2 that, in combination with the inhibition of IKK $\alpha$ activity, could be profitably tested in therapeutic trials for treatment of human hormoneresponsive breast cancers.

\section{Conflict of Interest}

The authors declare no conflict of interest.

Acknowledgements. This work has been supported by the Associazione per la Ricerca sul Cancro (AIRC Grant IG 11520: PI Antimo Migliaccio).

\author{
B Perillo*, ${ }^{*}$ A Di Santi , G Cernera ${ }^{2}$, MN Ombra $^{1}$, G $^{2}$ Castoria $^{2}$ and \\ A Migliaccio $^{2}$ \\ ${ }^{1}$ Istituto di Scienze dell'Alimentazione, C.N.R., Avellino, Italy and \\ ${ }^{2}$ Dipartimento di Biochimica, Biofisica e Patologia Generale, \\ Seconda Università degli Studi di Napoli, Naples, Italy \\ *Corresponding author: B Perillo, Istituto di Scienze dell'Alimentazione, Consiglio \\ Nazionale delle Ricerche, via Roma, 52, 83100 Avellino, Italy. \\ Tel: + 390825 299210; Fax: + 390825 781585; E-mail: perillo@unina.it
}

\author{
1. Fischle W, Wang Y, Allis CD. Nature 2003; 425: 475-479. \\ 2. Rea $S$ et al. Nature 2000; 406: 593-599. \\ 3. Metzger E et al. Nature 2005; 437: 436-439. \\ 4. Park K-J et al. Mol Cell 2005; 18: 71-82. \\ 5. Perillo B et al. Science 2008; 319: 202-206. \\ 6. Roldan-Arjona T et al. Proc Natl Acad Sci 1997; 94: 8016-8020 \\ 7. Pierce JW et al. J Biol Chem 1997; 272: 21096-21103. \\ 8. Metivier $\mathrm{R}$ et al. Cell 2003; 115: 751-763.
}

\begin{abstract}
(c) (i) (S) $\odot$ This work is licensed under a Creative Commons Attribution-NonCommercial-NoDerivs 3.0 Unported License. The images or other third party material in this article are included in the article's Creative Commons license, unless indicated otherwise in the credit line; if the material is not included under the Creative Commons license, users will need to obtain permission from the license holder to reproduce the material. To view a copy of this license, visit http://creativecommons.org/licenses/by-nc-nd/3.0/
\end{abstract}

